\title{
Identidad cultural y desarrollo urbano: ¿proyectos engañosos?
}

\author{
Identidade cultural e desenvolvimento urbano: projetos falaciosos?
}

\author{
Cultural identity and urban development: deceptive projects?
}

\author{
Luiz Augusto F. Rodrigues
}

\author{
Palabras clave: \\ Identidad \\ Gestión del espacio \\ urbano \\ Gestión cultural \\ Turismo cultural
}

\section{Resumen:}

La investigación - cuyos resultados parciales presenta esta ponenciadesarrolla ideas sobre la construcción y consolidación del Camino Niemeyer, atracción turística en Niterói, ciudad del Estado de Rio de Janeiro, Brasil. Tengo el objetivo de evaluarlo como un gran proyecto de desarrollo urbano (GPDU) viendo sus implicaciones socio-culturales en la ciudad. En general, la investigación busca seguir manifestaciones culturales tengan una fuerte capacidad de atraer turismo y evaluar cuál es su capacidad (o no) para fortalecer el desarrollo local. Uno de los principales desafíos de las políticas culturales, sobre todo en Brasil, es fortalecer la dimensión económica de la cultura, sin perjudicar sus dimensiones simbólicas y ciudadanas. Con el turismo cultural como motivo, en esta propuesta se puede observar el fortalecimiento de la dinámica económica sostenida por los valores culturales simbólicos y ver como tales intervenciones urbanas activan (o no) las prácticas de sociabilidad. La metodología de investigación consiste en el trabajo de campo, observación participante, entrevistas y noticias en periódicos. Los proyectos de consolidación de esta ciudad tan fuertemente marcada por los diseños del arquitecto Oscar Niemeyer son recurrentes en la planificación urbana y turística del municipio de Niterói, lo que creemos que fortalece la consolidación de nuevos valores identitarios asentados en iconos urbanos modernos. 


\section{Resumo:}

A pesquisa - cujos resultados parciais são apresentados neste artigo - discute a construção e consolidação do Caminho Niemeyer, atração turística em Niterói, cidade do estado do Rio de Janeiro, Brasil. Buscase avaliá-lo como um grande projeto de desenvolvimento urbano (GPDU) vendo suas implicações sócio-culturais da cidade. De modo geral, a pesquisa pretende identificar manifestações culturais que têm forte capacidade para atrair turistas e avaliar sua capacidade (ou não) para fortalecer o desenvolvimento local. Um dos principais desafios das políticas culturais, especialmente no Brasil, é reforçar a dimensão econômica da cultura, sem prejudicar suas dimensões simbólica e cidadã. Com o turismo cultural como foco, esta proposta visa entender a dinâmica econômica sustentada por valores culturais simbólicos e ver como tais intervenções urbanas podem ativar (ou não) as práticas de sociabilidade. A metodologia de pesquisa consiste em trabalho de campo, observação participante, e entrevistas e análise de notícias nos jornais. Projetos de consolidação urbana tão fortemente marcados pelos desenhos do arquiteto Oscar Niemeyer são recorrentes nos planejamentos turístico e urbano do município de Niterói, o que acreditamos possa reforçar a consolidação de uma nova identidade assentada em ícones urbanos modernos.

\section{Palavras chave:}

Identidade

Turismo cultural

Gestão do espaço urbano

Gestão cultural

\section{Keywords:}

Identity

\section{Urban management \\ Cultural management}

Cultural tourism

\section{Abstract:}

This research - whose partial results are presented in this paper develops ideas about the construction and consolidation of the Niemeyer Route, tourist attraction in Niteroi, a city of the State of Rio de Janeiro, Brazil. This is evaluated as a major project of urban development (GPDU) seeing its socio-cultural implications in the city. In general, the research seeks to follow cultural manifestations to understand the touristic attractivity and to evaluate what is its ability (or not) to strengthen local development. One of the main challenges of cultural policies, especially in Brazil, is to strengthen the economic dimension of culture, without harming their symbolic and citizens dimensions. Aiming cultural tourism, our proposal is to identify the strengthening of the economic dynamics sustained by symbolic cultural values and to understand how such urban interventions activate (or not) the practices of sociability. The research methodology consists of the work of field, participant observation, interviews, and news in newspapers. Consolidation projects in this city so strongly marked by the designs of the architect Oscar Niemeyer are recurrent in tourist and urban planning of the municipality of Niterói, which - we believe is consolidating new identity values on modern urban icons. 


\section{Identidad cultural y desarrollo urbano: ¿proyectos engañosos?}

Vir para a cidade grande é, certamente, deixar atrás uma cultura herdada para se encontrar com uma outra. Quando o homem se defronta com um espaço que não ajudou a criar, cuja história desconhece, cuja memória lhe é estranha, esse lugar é a sede de uma vertiginosa alienação. (SANTOS, 2014, p. 328)

\section{Niterói y los proyectos de Oscar Niemeyer}

Niterói fue la capital de la provincia de Rio de Janeiro hasta $1975^{i i}$. La pérdida del status de capital trajo un vaciamiento político y un estancamiento en diversos sectores e instituciones. Si analizamos la sociedad vemos que hubo una sensación de pérdida de identidad. Esta situación empezó a cambiar con la elección del alcalde Jorge Roberto Silveiraiii, que buscó consolidar la imagen de la ciudad con unos valores socioeconómicos distintos y con unos valores artístico-arquitectónicos atractivos. La condición socioeconómica de la ciudad queda expresada en la quinta posición en relación a la calidad de vida según el ranking IDHM. Para conseguir una ciudad artística y arquitectónicamente atractiva se buscó a Oscar Niemeyer, a quien se le solicitó el proyecto del Museu de Arte Contemporânea / MAC.

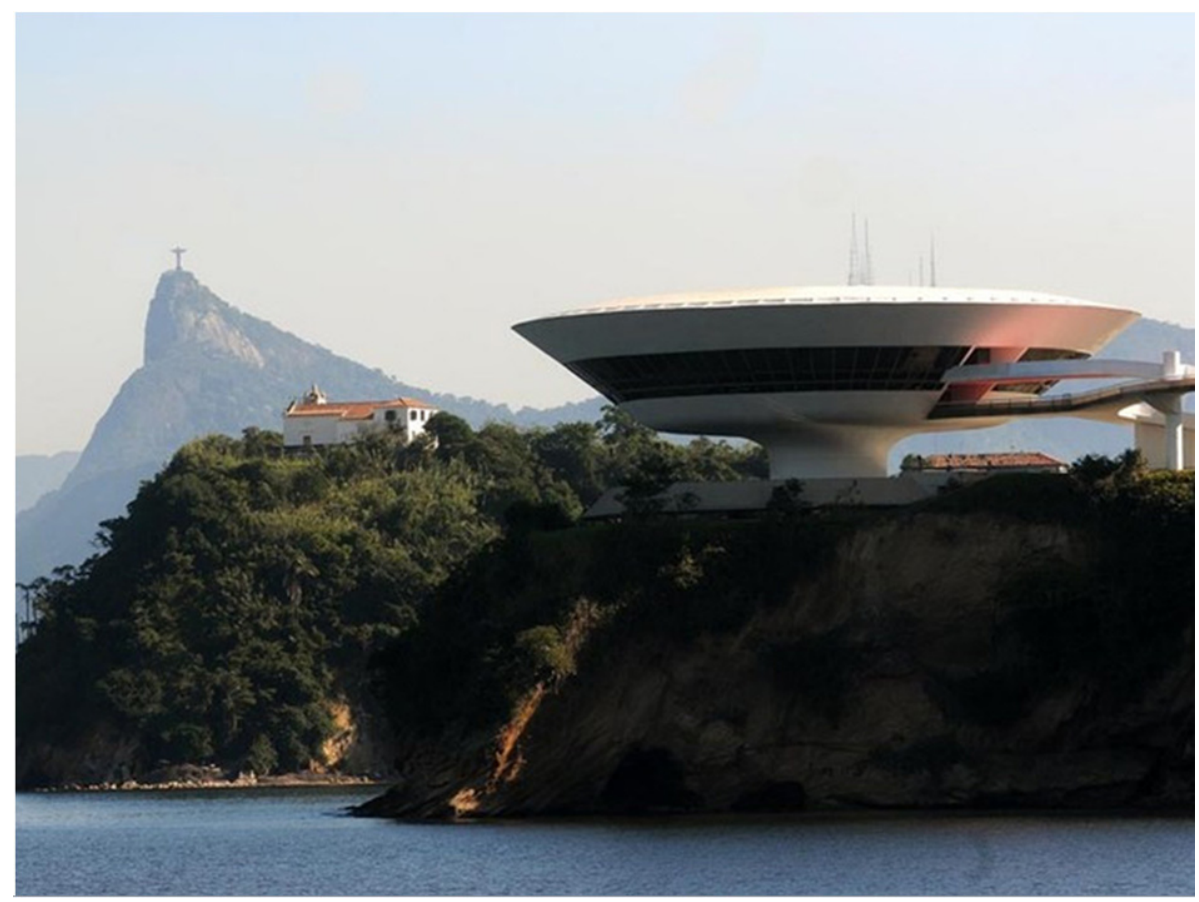

MAC / Museu de Arte Contemporânea - Boa Viagem, Niterói - Brasil Fuente: https://www.google.com.br/url, Acceso el 01/02/2015 


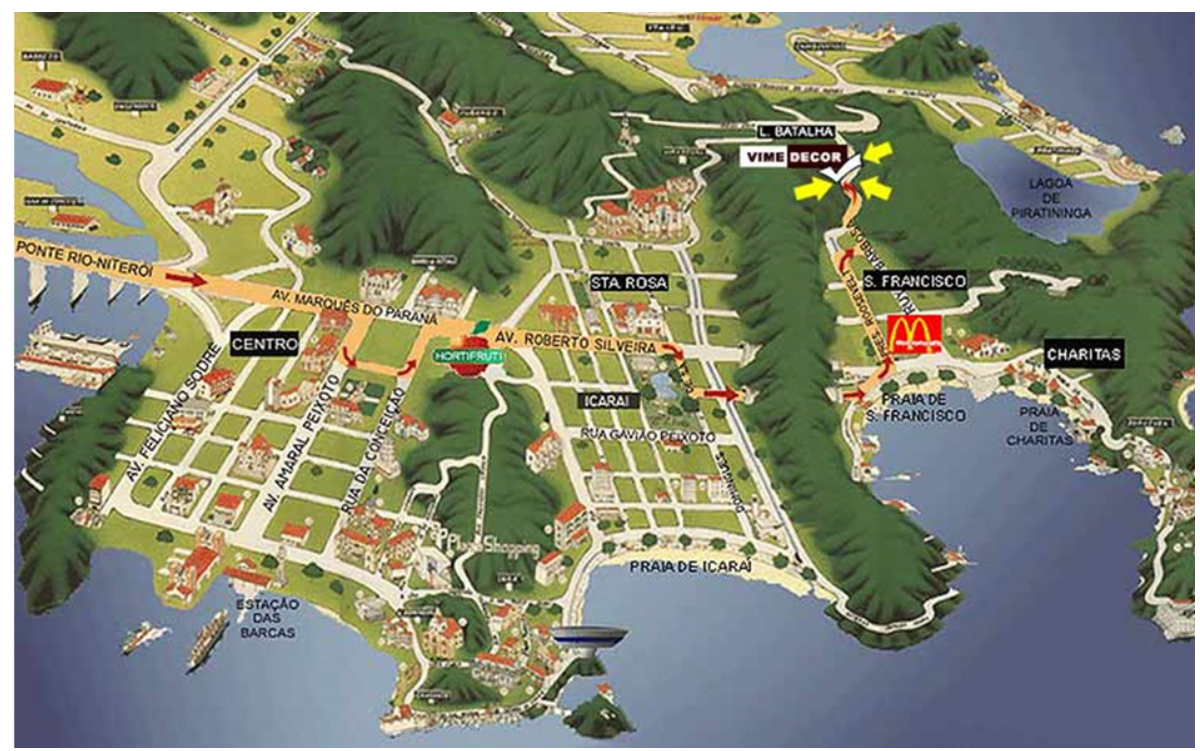

Véase en el inferior al centro la ilustración del MAC, ubicado en un mirador en el barrio Boa Viagem Fuente: http://2.bp.blogspot.com/-JFN7kieB14E/Tbg1Xw8spEI/AAAAAAAAACc/55KciMg5BS8/s1600/mapa.jpg. Acceso el 01/02/2015

He estado investigando la ciudad de Niterói, en especial sus valores culturales y patrimoniales, y es muy evidente la asunción del significado del MAC en el imaginario niteroiense. Busco entender el hecho urbano como resultado de la producción de diversos actores sociales, cuyas ambigüedades y fantasías deben ser reveladas. Y, también, destacar que las expectativas de los usuarios de las ciudades son construidas culturalmente, pero que son, también, representaciones inducidas ideológicamente. Los estudios sobre titulares y artículos de periódicos pueden ser bastante representativos del poder que tienen de los discursos en la constitución de imaginarios. Veámos ejemplos de titulares de prensa extraídos del dominical del periódico O Globo (separata Niterói).

En 1993 los periódicos todavía enunciaban "Clima interiorano atrai cineasta" (O GLOBO, 04/06/93), pero pocos años después lo singular cedía su lugar a lo sorprendente: "Cidade em foco - MAC entrou na última hora nas gravações" (10/05/98). Si en 1995, la marca de la identidad urbana aun se asentaba en el imagen del indio Araribóia, figura importante en la fundación de la ciudad y que marca sus raíces ("Araribóia - um cacique feliz com a sua aldeia" -19/11/95), tres años después pasan a destacar nuevos símbolos. Son símbolos de la modernidad (o de la posmodernidad?). Son imágenes sin vivencia. El MAC, ícono del marketing urbano, es el "Garoto propaganda" (25/07/99) que provoca "Paixão pelo símbolo cultural da cidade" (26/09/99) y coloca a Niterói en el mapa cultural de Brasil (quizá del Mundo).

Oscar Niemeyer tiene el mérito de ser un creador/constructor de la identidad artística brasileña desde 1940iv. En el caso de Niterói, la consolidación del ícono ciudadNiemeyer fue rápida. En un principio nadie lo entendía muy bien. ¿Qué representaba la forma del Museo? Un platillo volante, afirmaban los más ufólogos. Un cáliz sagrado, rebatían los más metafísicos. Y una vez más, los reportajes del dominical Globo Niterói vienen a tejer el imaginario a través del discurso. Jocoso, inicialmente. Enseguida, consolidado. Aquellos que esbozaron una sonrisa con el discurso inicial tuvieron 
que ceder al imaginario general. La secuencia de titulares presentada apunta hacia este cambio. "MAC está prestes a decolar" (01/10/95) o "O cálice está quase pronto para a festa" (28/07/96) no fueron titulares muy acordes a la marca de nuestro mayor poeta/constructor. Fueron dejadas a un lado. Las sustituyeran otros discursos más competentes: "MAC transforma Niterói em pólo turístico" (09/03/97); "Uma cidade com a grife Oscar Niemeyer" (04/05/97); "Caminho Niemeyer rumo ao futuro” (11/07/99).

La ciudad siguió ganando nuevas obras firmadas por Niemeyer. Algunos intentaron llamar la atención sobre problemas que los entusiastas urbanistas no conseguían ver. Los daños ambientales que el terminal de la hidrovía de Charitas proyecto de Niemeyer en el punto extremo de la costa niteroiense a lo largo de la baía de Guanabara - podría ocasionar, fueron imaginados, como señalan los reportajes "Novo terminal está em rota polêmica" y "Mar de reclamações: pescadores atacam a proposta e ONG pede estudo de impacto" (ambas de 20/09/98). Puras voces calladas. Al final, desde la llustración el hombre viene apoyándose en su magnitud sobre la naturaleza. Cabe a esta someterse a nuestras voluntades, a nuestras fantasías imaginarias. Y aún para terminar con el MAC, "Mar serve de moldura para a foto perfeita" (15/11/98) prueba que la cuestión ambiental sirve, como mucho, como telón de fondo suplantado por la cuestión icónica.

He participado en el tribunal de máster de Porto Junior (2009), cuyo trabajo nos hace reflexionar sobre los descaminos de la sociedad contemporánea. La tesina, oportuna y necesaria, realza algunas dimensiones de los GPDUs: Grandes Proyectos de Desarrollo Urbanov.

Al observarse determinados GPDUs, podemos empezar a hacernos algunas preguntas: que son Grandes Proyectos, no hay ninguna duda; si son de
Desarrollo, eso puede cuestionarse. Ciertos términos necesitan ser siempre cuestionados. Desarrollo ¿de qué?; ¿A partir de qué modelo?; ¿Con qué finalidad?; ¿Un planeamiento estratégico para quién?; ¿Con quién y por quién? Algunos de estos temas orientan algunas de mis reflexiones.

Porto Junior recurre a las discusiones sobre la sociedad del espectáculo de Guy Debordvi, estableciendo correlaciones entre determinadas materializaciones de la sociedad contemporánea. $Y$ es en este campo que quiero avanzar, pues de alguna forma tanto la Cultura como el Urbanismo son travestidos en sus sentidos esenciales y transformados en merchandising en una sociedad que parece centrarse solamente en el consumo y en la imagen.

Desde mi punto de vista, los GPDUs normalmente son fruto de esta postura consumista, produciendo espacios efímeros y simplemente espectaculares. La lógica de los grandes escenarios urbanos dan cuenta del planeamiento actual. Los espacios urbanos son pensados en cuanto escenarios, valen por su carga significante, su imagen... En muchos de los proyectos falta tener en cuenta a los actores que darán vida a la escena; y estoy hablando de protagonistas y no de meros figurantes. De otro modo, se convierte solamente en el escenario mismo. Se vuelve no-lugar, en la acepción del antropólogo Marc Augé [1992] ${ }^{\text {vii. Lugar de }}$ paso, sin enraizamiento, sin vivencia.

Pensar en la producción de esta tipología de espacios urbanos es como pensar en el tipo de producción de arte y cultura que aún insiste en ser dirigida solamente al "consumo" inmediato. Del mismo modo que necesitamos acciones en cultura que deseen que los individuos sean fruidores, dando uso efectivo, apropiándose... Ser, al contrario de solo parecer. Mirar, a invés de solo ver. Vivenciar, al contrario de solo estar. O sea, acciones que "huyan" de lo meramente eventual y efímero. 
Todo indica que los GPDUs tienen la misma lógica de una industria cultural dirigida apenas al consumo de masa. Ambos quieren solo el "espectáculo". Ambos quieren que solo lo eventual consolide el imagen, la marca. Ambos se pautan por apropiaciones meramente mercadotécnicas?. No quiero ser pesimista; quiero defender una lógica contraria. Quiero que Arte y Manifestaciones Culturales sean lo que son: posibilidades múltiples de ejercicio de nuestra posibilidad de conmoción, de encantamiento. Quiero que los Lugares Urbanos sean espacios de sociabilidad, de interacción, de práctica y vivencia. $Y$ no es mera cuestión panfletaria; és cuestión de cómo posicionémonos en el mondo. Se trata aquí de la defensa de que no hagamos de nuestras vidas meras representaciones (individuales), meros escaparates de exposición (en el cual el sujeto si torna un producto, objeto), meras imágenes (virtuales o reales)... espejismos...

Según los trabajos académicos (el citado, y otros), el Camino Niemeyer es un GPDU. Un gran proyecto urbano, fruto de poderosas sociedades público-privadas, un ejemplo del empresariamiento urbano, una marca de diseño en la lógica del citymarketing, un no-lugar en la concepción de Augé, un espectáculo consumible en la concepción de Debord, un lugar segregado en mi concepción; en suma: una catástrofe. Preferiría un lugar-común, un simple lugar. Integrado al resto de la ciudad. Si proyectar calidad estética es producir ese tipo de morfología, prefiero la simplicidad de las formas urbanas vernáculas... Los planificadores y gestores (tanto urbanos como culturales) tienen que "aprender" que las acciones en cultura y producción de territorios necesitan asentar su fuerza y su atractivo más allá del gran evento, atrayendo turistas y población local. Planear según la lógica de la vivencia y no del "espectáculo".

Las áreas centrales, así como las áreas que perdieron su función a lo largo del tiempo (como zonas portuarias, por ejem- plo) han sido objeto recurrente de la recalificación urbanistica, en especial sacando provecho de la implantación de espacios culturales monumentales. Tales intervenciones tienen, muchas de las veces, desconsiderada la manutención del tejido social existente, enfocando prioritariamente ampliación de sectores y nuevas camadas sociales.

Mezclar edificaciones nuevas con edificaciones antiguas o históricas, potenciar dinámicas sociales que abarquen grupos diferentes, promover intervenciones de pequeña dimensión e incluir la mejoría de los espacios colectivos, son acciones que me parece que apuntan hacia mejores posibilidades y resultados al intervenir en los centros urbanos. Del mismo modo que en cualquier área de la ciudad. Lo que no está siendo la lógica orientadora de las intervenciones contemporáneas. Veremos que el caso del Camino Niemeyer y del centro de Niterói no si alejan de eso...

\section{Oscar Niemeyer y la identidad brasileña}

Desde los años cuarenta esta siendo relevante y importante lo que la obra del arquitecto Oscar Niemeyer representa, no solo en la divulgación del arte arquitectónico moderna/modernista brasileña y internacional, sino también en el sentido de que su obra es esencial para el fortalecimiento de la propia valorización de la identidad artística brasileña, asimismo y, sobretodo, entre nosotros mismos una vez que venia avalada internacionalmente.

Todavía hoy, si cogemos - por ejemplo - una publicación francesa dedicada a la arquitectura universal, con fecha de 2009 viii, en sus 959 páginas dedicadas a presentar, a través sobre todo de imágenes, la selección de las más bellas arquitecturas, de las pirámides egipcias al estadio olímpico de Pekín (de 2008), la publicación presenta seis obras de Niemeyer, ilustrándole en la 
misma cantidad que a Frank Lloyd Wright, Renzo Piano, Jean Novel, Zaha Hadid, Frank Gehry y Alvar Aalto.

Marshall Berman (1986) caracteriza las modernidades como condenadas a deshacerse en el aire. El modernismo del siglo XIX es dialéctico: al mismo tiempo que denuncia los peligros de la vida moderna, cree que las modernidades del mañana pueden curar las heridas; el del siglo XX pierde los enlaces entre la cultura y la vida: o si es acrítico sobre la modernidad o escéptico y indiferente. Esta es siempre vista como un "monolito cerrado", caminos que no se entrecruzan: tradición vista como esclavitud, modernidad como libertad. Iniciamos el siglo XXI con perspectivas aún más desoladoras, con todo girando en torno a la valorización del mercado: tradición y historia sedimentan procesos de museificación de las ciudades; planos estratégicos que gentrifican y ennoblecen los espacios. J. Habermas (2002) entiende la modernidad como un proyecto inacabado, ya que el hombre aún no alcanzó sus posibilidades potenciales. F. Jameson (2006), por su parte, ha desarrollado una larga argumentación en el sentido de que, hoy, las subjetividades están inmersas en algo que difiere de la razón ilustrada, demarcando en esa coyuntura un proceso de ruptura con la modernidad.

He observado, a través de recientes investigaciones, que la arquitectura y el urbanismo modernistas, en Brasil, dejaron marcas profundas en nuestra identidad. Profundas hasta el punto de que constituyeron obstáculos frente a la proposición de nuevas alternativas (RODRIGUES, 2001). Pretendo, aquí, en este momento, dibujar algunos de los caminos del establecimiento de ese fuerte trazo cultural. La trayectoria de la arquitectura moderna brasileña la consubstancio como elemento determinante de nuestra identidad: capaz de colocarnos en el rol de las mejores producciones artísticas del mundo, la arquitectura modernista ha cristalizado en las figuras de esos grandes mentores (RODRIGUES, 2000).

\section{Ciudad contemporánea: segregación ¿disfrazada?}

Hasta aquí, buscamos caracterizar la fuerza de la arquitectura moderna brasileña y cómo pudo ser importante para la estructura de la identidad artística brasileira y su reconocimiento, nacional y internacional. En este aspecto, el arquitecto Oscar Niemeyer tuvo una importancia única, constituyéndose como el principal representante de la arquitectura moderna brasileña (hasta hoy), y uno de sus principales exponentes mundiales.

Buscamos, aún, reflexionar sobre la producción del espacio urbano, apuntando los caminos seguidos a lo largo del siglo pasado y cada vez más hasta hoy, que vienen consolidando espacios uniformizantes (sobretodo en relación a las prácticas sociales en ellos propiciadas), al mismo tiempo que "travestidos" como espacios heterotópicos (FOUCAULT, 2013). Tal discurso es aplicado sobre la lógica del planeamiento estratégico y la espectacularización del espacio en la contemporaneidad que esta siendo utilizado cada vez más de edificios proyectados por grandes exponentes de la arquitectura mundial, en especial los dedicados a funciones culturales (museos, teatros etc.).

En el punto siguiente, buscaremos enfocar el turismo cultural, el empresariamiento urbano y la mercantilización del uso del suelo, articulandolos como grandes vectores que son la base de la producción de las identidades urbanas contemporáneas, seguiendo aún con el ejemplo de la consolidación del Camino Niemeyer, en Niterói.

La imagen siguiente presenta el área de aterro donde fue construido el Camino Niemeyer, es una simulación con la verticalización deseada para el contexto del proyecto. 


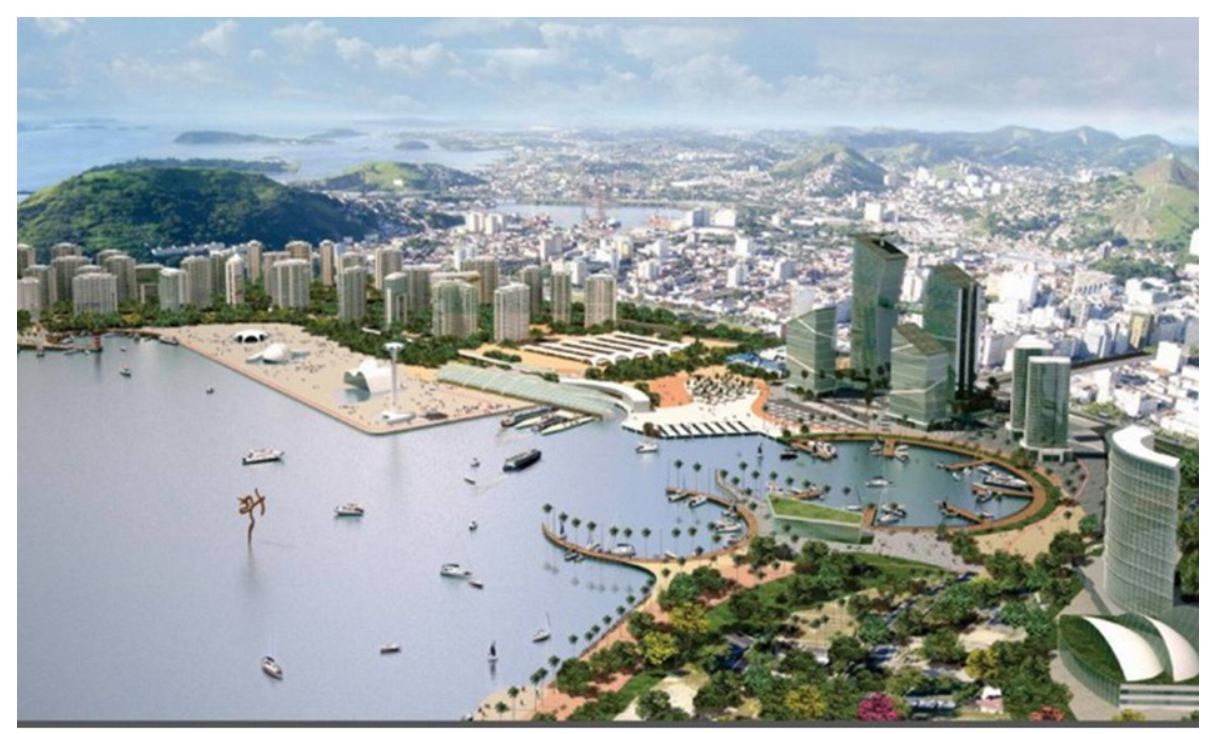

Imagen divulgada por la Prefeitura de Niterói.

Fuente: http://og.infg.com.br/in/14630484-b65-27c/FT1086A/420/2013-619751352-013060709570.jpg_20130609.jpg

\section{Las tres "e" de la dimensión cultural y el enfoque en su dimensión económica}

La investigación enfocan el Camino Niemeyer, en Niterói, viéndolo como una expresión cultural que debe ser entendida en su triple dimensión: 1. dimensión estética (o simbólica): la figura del arquitecto Oscar Niemeyer representando, como hemos visto, la construcción de identidad artística para el país; 2. dimensión ética (o ciudadana): el Camino Niemeyer en cuanto espacio público podría configurarse como un importante lócus de interacciones sociales, aunque - conforme ya hemos apuntado - este espacio urbano ofrece condiciones de sociabilidad débil, dialogando con conceptos como el de nolugar y de empresariamiento urbano a través de los GPDUs (Grandes Proyectos de Desarollo Urbano); dimensión económica: la investigación esta averiguando datos sobre la dinámica inmobiliaria de Niterói, buscando percibir el impacto en los barrios que cuentan con obras de este arquitecto. En oposición, al atractivo turístico y simbólico del Camino Niemeyer podría representar para la ciudad y sus practicantes (en la concepción de Michel de Certeau (2008) posibilidades de mayor vitalización y cualificación de sus entornos urbanos; lo que no parece suceder.

Creo que el mayor desafío es conseguir mantener/fomentar/activar las dimensiones estética y ética, por mucho que la sociedad contemporánea busque reforzar a la dimensión económica. Estoy procurando entender los conceptos de gestión cultural y de gestión urbana articulandolos con los conceptos de redes de sociabilidad y de mediaciones. Mediación de procesos de producciones materiales e inmateriales de bienes culturales y mediación de agentes sociales más diversos. Mediación que busca estimular los procesos de creación y disfrute de bienes culturales, así como estimular las prácticas de cohesión social y de sociabilidadix.

Este tema de investigación fue objeto de un proyecto desarrollado en $2014^{x}$, en el cual entre la metodología empleada en el intento de entender mejor los procesos económicos ocurridos en los espacios urbanos que contienen proyectos de Nie- 
meyer podemos destacar: a) Investigación de reportajes publicados en los principales periódicos diarios que circulan en la ciudad - periódicos O Fluminense, O Globo, y Jornal do Brasil (en los años 2013 y 1014) - indexando sus temas, en especial los que tratan de la consolidación del Camino Niemeyer en cuanto atractivo turístico; b) Investigación de la cantidad de oferta de inmuebles para venta y alquiler en los barrios niteroienses que cuentan con obras de Niemeyer (a saber: Centro, São Domingos, Boa Viagem y Charitas); enfocamos las investigaciones en los años de inauguración de las construcciones, comparando los valores de aquellos años con 5 años antes y 5 años después; c) Investigación de los valores del $\mathrm{m}^{2}$ construido en los barrios con proyectos Niemeyer, en una perspectiva comparada entre los años de 2011 y 2014, y comparando los valores de 2014 en relación a los diversos barrios de la ciudad y a media urbana.

Nos últimos anos a cidade de Niterói sofreu um grande aumento no preço e na quantidade de construções imobiliárias, foram 4.784 unidades lançadas em 43 empreendimentos em 2011. Para justificar este fenômeno, alguns artigos do jornal "O Fluminense" entre 2011 e 2014 dão crédito a diversos eventos. A Copa do Mundo, as Olimpíadas e o Complexo Petroquímico do Estado do Rio de Janeiro (Comperj) estão entre as principais razões.

O Caminho Niemeyer é raramente citado como causa deste "boom" imobiliário, mas uma pesquisa feita do acervo dos classificados do jornal "O Fluminense" aponta um crescimento contínuo de ofertas para compra/venda nos bairros onde se localizam as obras de Niemeyer. Aqui se encontra o exemplo da região da Boa Viagem, onde o Museu de Arte Contemporânea foi inaugurado em 1996:
É possível ver um efeito parecido nos gráficos da região do Gragoatá (bairro que também conta com obra projetada por Niemeyer), já no bairro Ingá (próximo aos demais, mas sem a grife Niemeyer a marcar suas ruas) o mercado imobiliário parece ter se comportado de maneira inversa (RODRIGUES ; SILVA, 2014).

La cuestión de la sociabilidad y de un mayor uso público del Camino Niemeyer se incorporó en las estrategias presentadas por la gestión municipal a partir de 2013 , pero con muy poca efectividad hasta ahora. Como apuntamos en un informe interno de la investigación desarrollada junto al OBEC-RJ:

Seria falacioso dizer que não existem políticas voltadas para a divulgação do Caminho Niemeyer e atrair visitantes. Ao manter um registro sobre a movimentação do local durante seis meses, foi possível observar que houve um esforço para a realização de mais eventos e promoção de visitas guiadas para turmas de escolas públicas. Contudo, estas políticas costumam ser falhas e acabam por não atingir os objetivos esperados, vejamos agora dois exemplos.

A primeira intervenção de que vamos tratar foi a construção da passagem do terminal rodoviário até o Caminho, inaugurada em meados de julho de 2013, e que facilita o acesso de pedestres, em especial os usuários do terminal. $\mathrm{Na}$ fala do prefeito Rodrigo Neves, esta integração possibilitaria à população mais pobre maior facilidade de fruição das obras: "Com esse projeto, a população mais pobre poderá usufruir deste extraordinário conjunto arquitetônico do Oscar Niemeyer"xi. No entanto, de acordo com os dados fornecidos pelo Centro de Atendimento ao Turista, a passagem não influencia em quase a nada a frequência de vi- 
sitação no local. Além disso, é possível que grande parte desta população mais pobre não se sinta a vontade em um lugar como este, o que não corrobora com a fala do prefeito.

Outra intervenção, esta mais recente, foi a construção de um castelo de areia, erguido com o objetivo de entrar para o livro dos recordes como o maior castelo de areia do mundo. Segundo uma matéria do jornal "O
Fluminense", o castelo iria ser inaugurado no dia 12/11/2014, uma quarta-feira, e a visitação seria até o dia 22 do mesmo mês ${ }^{\text {xii }}$. O feito deveria atrair público e divulgar o Caminho, assim como a cidade de Niterói, mas quem chegou lá do dia 12 só conseguiu ver o castelo desmontado, pois no dia anterior foi realizada a medição oficial para análise e logo em seguida a escultura foi derrubada. (RODRIGUES ; SILVA, 2014b)

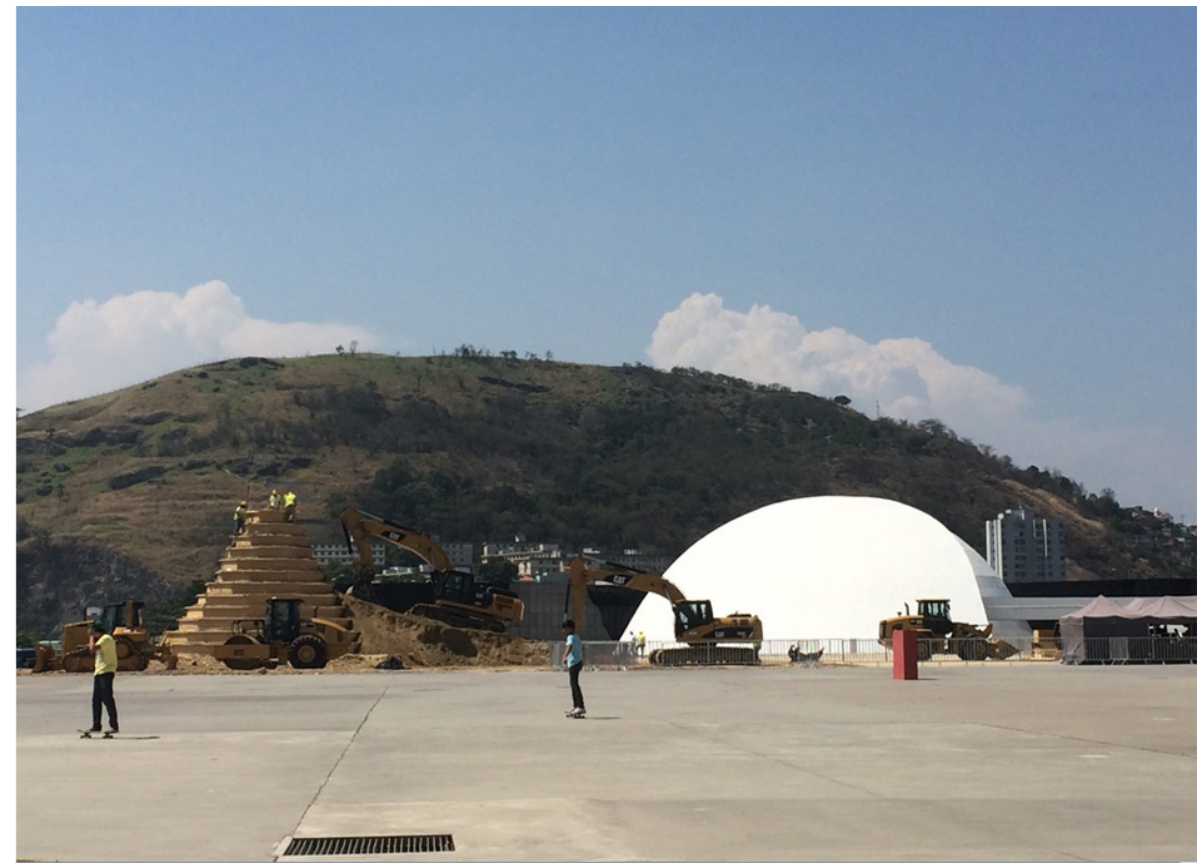

Construcción del Castelo de Areia en el Camino Niemeyer 02/11/14 - Acervo propio de la investigación.

\section{Consideraciones finales preliminares}

Pensar en la Cultura y en su papel en el desarrollo de un país, región, comunidad, o de las personas en general se ha transformado radicalmente en las últimas décadas suponiendo desafíos inéditos e inmensos para todos aquellos que, en el sector público o en el sector privado, buscan nuevos caminos, soluciones y funciones, tanto para los tradicionales, como para los nuevos territorios de la cultura. $Y$ es en el espacio de la ciudad que la multiplicidad de las relaciones acontecen mejor. La ciudad es el núcleo central de todo acontecer social y concentra en si la atención y las prácticas de investigación sociológicas, económicas y culturales más precisas. Las ciudades son espacios de sociabilidades múltiples y de intensas relaciones multiculturales. Poblaciones y arquitecturas híbridas se propagan y se concentran espacial- 
mente en constelaciones de manzanas, barrios, servicios, y redes diversas de circulación. La naturaleza de los mecanismos de producción y circulación de información, la complejidad social de las capas poblacionales, el tipo de relación que mantienen con otras redes de ciudades, los nuevos esquemas de relaciones territoriales, los movimientos e intercambios culturales, las nuevas formas y valores exigen nuevas miradas sobre esta realidad, a través de las cuales la articulación de las disciplinas tradicionales pueda ser revista para dar sitio a otros instrumentos y otros abordajes teóricos e instrumentales.

Al considerar el turismo cultural y determinadas estrategias de uso del espacio público para manifestaciones culturales y de producción de arte colectiva estamos apuntando y queriendo percibir/ descubrir posibilidades de reversión de la lógica contemporánea que crea más indiferencia urbana que acciones de apropiación y convivencia. Hay que destacar el papel simbólico de los centros. Son ellos, normalmente, los que remiten a los orígenes históricos de las ciudades. Una alerta desde ahora: lo que aquí se señala al hablar de manutención y rescate de la memoria no tiene nada que ver con la tendencia apuntada por Andreas Huyssen (2000): "restauración historizante de viejos centros urbanos, ciudades-museos". No es la memoria en cuanto producto rentable de la industria cultural que se debe buscar, y sí más las relaciones interpersonales que el pasado posibilitó, y la deconstrucción del no-sujeto posmoderno a través del rescate de la identidad.

Se puede entender cultura como un proceso de sedimentación de memorias a largo y a medio plazo - y que opera con las diferencias de toda la sociedad. Entendiendolo de esta forma sus propósitos son contrarios a los de la lógica de mercado - entendiendo esta por su búsqueda de inmediatismo y estandardización.
Referido a la estrategia metodológica algo importante es que se debe congregar instancias públicas y sociales, y su integración a movimientos originarios de la sociedad civil. El caso metodológico del Camino Niemeyer nos parece potente, pues permite un acompañamiento más constante, con entrevistas y reportajes de periódicos - ya que el proyecto del Camino vuelve a la escena del planeamiento urbano y turístico del municipio. Lo que queremos argumentar es que determinados modelos de planificación turística y cultural pueden sobrepasar y a su vez destruir el potencial de los territorios, reaccionando - por lo tanto - en la contra-mano de lo que deberían potenciar.

\section{Bibliografia:}

AUGÉ, Marc. Não lugares: introdução a uma antropologia da supermodernidade. 9. ed. Campínas, SP : Papirus, 2012.

BERMAN, Marshall. Tudo que é sólido desmancha no ar. a aventura da modernidade. São Paulo : Cia. das Letras, 1986.

CERTEAU, Michel de. A invenção do cotidiano: 1. Artes do fazer. Petrópolis, RJ : Vozes, 2008.

DEBORD, Guy. A sociedade do espetáculo. Rio de Janeiro : Contraponto, 1997.

FOUCAULT, Michel. O corpo utópico, as heterotopias. São Paulo : n-1 Edicões, 2013.

HABERMAS, Jürgen. O discurso filosófico da modernidade. São Paulo : Martins Fontes, 2002.

HUYSSEN, Andréas. Seduzidos pela memória: arquitetura, monumentos, mídia. Rio de Janeiro : Aeroplano, 2000.

IRVING, Mark (dir). Les 1001 merveilles de l'architecture: qu'il faut avoir vues dans as vie. Paris : Flammarion, 2009.

JAMESON, Fredric. Pós-modernismo, a lógica cultural do capitalismo tardio. São Paulo : Ática, 2006. 
PORTO JR., João Batista. Refazendo o Caminho: dimensões do projeto urbano de Niemeyer, RJ. Niterói : Universidade Federal Fluminense, 2009. Dissertação de mestrado em Arquitetura e Urbanismo.

RODRIGUES, Luiz Augusto F. Arquitetura modernista como traço da identidade brasileira. Poiesis, Niterói, v. 1, n. 1, 2000. p. 79-88.

RODRIGUES, Luiz Augusto F. Universidade e a fantasia moderna: a falácia de um modelo espacial único. Niterói, RJ : EdUFF, 2001.

RODRIGUES, Luiz Augusto F. Gestão cultural e seus eixos temáticos. In: CURVELLO, M. A. [et al] (orgs). Políticas públicas de cultura do Estado do Rio de Janeiro: 2007-2008. Rio de Janeiro : Uerj/ Decult, 2009. p. 76-93.

RODRIGUES, Luiz Augusto F. Gestão cultural e diversidade: um ponto de cultura em estudo. In: FRADE, Cáscia [et al] (orgs). Políticas públicas de cultura do Estado do Rio de Janeiro: 2009. Rio de Janeiro : Uerj/Decult, 2012. p. 143-158.

RODRIGUES, Luiz Augusto F. O lugar da cultura. A cultura do lugar. PragMATIZES - Revista LatinoAmericana de Estudos em Cultura, Ano 3, n 4, 2013. p. 76-91. Disponible en: www.pragmatizes.uff.br

RODRIGUES, Luiz Augusto F. y SILVA, Mariana Leite. (Cultura e espacialidade em Niterói: reflexões preliminares. In: Encontro Brasileiro de Pesquisa em Cultura (2.: 2014 outubro 15-17...). Rio de Janeiro : Fundação Casa de Rui Barbosa, 2014. 1 CD-ROM.

RODRIGUES, Luiz Augusto F.y SILVA, Mariana Leite. Percepções sobre Ética e Estética no Caminho Niemeyer e nas Propostas de Revitalização do Centro de Niterói. [Informe interno enviado a la OBEC-RJ]. Niterói, 2014b. Circulación restringida.

SÁNCHEZ, Fernanda, BIENENSTEIN, Glauco y otros. Produção de sentido e produção do espaço: convergências discursivas nos grandes projetos urbanos. Revista Paranaense de Desenvolvimento, n. 107, jul/dez., 2004. p. 39-56.

SANTOS, Milton. A natureza do espaço: técnica e tempo, razão e emoção. São Paulo : Edusp, 2014. i Luiz Augusto Fernandes Rodrigues, Arquitecto, urbanista y doctor en historia. Catedrático de la Universidad Federal Fluminense, Brasil. Contacto: luizaugustorodrigues@id.uff.br

ii En 1975 las provincias Guanabara y Rio de Janeiro se convirtieron en una sola ciudad y Río de Janeiro pasó a ser capital de la nueva provincia. Así, Niterói, perdió el estatus de capital de lo que era conocido hasta ese momento como la provincia Rio de Janeiro.

iii Jorge Roberto Silveira estuvo en la alcaldía durante cuatro mandatos (1989-1992; 1997-2000; 20012001; 2009-2012), siendo realizada la construcción del MAC (Museu de Arte Contemporânea) durante su primer mandato.

iv Para más detalle sobre la trayectoria de Oscar Niemeyer, véase RODRIGUES 2000 e 2001.

v Estudios en profundidad sobre la cuestión de los grandes proyectos urbanos están siendo desarrollados por profesores del curso de Arquitectura y Urbanismo de la Universidade Federal Fluminense, en especial Fernanda Sánchez y Glauco Bienenstein (2004).

vi DEBORD, Guy. A sociedade do espetáculo. Rio de Janeiro: Contraponto, 1997.

vii AUGÉ, Marc. Não lugares: introdução a uma antropologia da supermodernidade. 9. ed. Campínas, SP: Papirus, 2012. Primera edición francesa de 1992.

viii IRVING, Mark (dir). Les 1001 merveilles de l'architecture: qu'il faut avoir vues dans as vie. Paris: Flammarion, 2009.

ix Sobre el tema, ver Rodrigues (2009; 2012; 2013).

x Proyecto Turismo cultural: território e economia, desarrollado junto al OBEC-RJ (Observatório de Economia Criativa do Estado do Rio de Janeiro), en el cual he trabajado en sociedad con Mariana Silva, alumna de la licenciatura en Producción Cultural de la Universidade Federal Fluminense.

xi Disponible en: http://www.niteroi.rj.gov.br/index. php?option=com_content\&view=article\&id=1686: parc eria-entre-a-prefeitura-de-niteroi-e-a-iniciativa-privadaintegra-o-terminal-joao-goulart-ao-caminho-niemeyer. Acceso en 04/12/2014.

xii Información disponible en:http://www.ofluminense. com.br/editorias/cidades/o-maior-castelo-de-areia-domundo. Acceso el 04/12/2014. 